\title{
UN CASO COMPRICADO: TENSIÓNS REPERTORIAIS NO TEATRO DE LEANDRO CARRÉ
}

Carlos-Caetano Biscainho-Fernandes Grupo ILLA, Universidade da Coruña doi:10.17075/tucmeg.2015.015 



\section{A XEITO DE PREMISAS}

O repertorio ${ }^{92}$ sancionado nun momento concreto dun sistema é o resultado inestábel da concorrencia de moitas forzas dispares que comparecen co interese de deslocar a centralidade do sistema cara a posicións próximas á que ocupan os axentes que exercen cada unha desas forzas simbólicas. ${ }^{93} \mathrm{E}$, como é lóxico, non todos os elementos integrados nunha rede de relacións poden despregar unha forza de igual intensidade.

Por exemplo, se non hai interferencias psicolóxicas, un falante vai tentar que a súa variante lingüística sexa a prestixiada (ou, no seu defecto, que continúe a ser aquela diferente da súa que, nunha etapa anterior da vida, o falante tivo que adquirir con esforzo para ascender socialmente). Da mesma maneira, un elemento institucional teimará en sancionar os itens de repertorio que reforcen a súa capacidade sancionadora ou, en todo caso, que non a poñan en dúbida. En última instancia, todos pretendemos que a nosa maneira de facer as cousas sexa a prestixiada, polo poder social que isto confire.

Por iso mesmo, a definición dunha centralidade repertorial activa dous tipos de respostas: un vector de forzas opostas ás mudanzas, que pon o seu esforzo na conservación do estado das cousas tal como están nese momento concreto; e, un outro vector rebelde e sedicioso, que teima en subverter esa situación e deslocar a centralidade a puntos do agregado repertorial agora periféricos, normalmente aqueles dos que se serve o axente concreto que está a activar esta forza centrífuga.

Estes fenómenos prodúcense igualmente nas etapas incipientes dun sistema, incluídos os literarios. Os encurtados modelos repertoriais sancionados nas etapas iniciais dun sistema emerxente $-e$, por tanto, aínda non completamente autónomo— ${ }^{94}$ exercen unha forza inmobilista, contraria a calquera vontade de introdución de fórmulas que alaguen, densifiquen e

92 Entendemos por «repertorio» a colectánea ordenada de elementos, regras e modelos que regulamentan a produción e consumo dun ben cultural (Even-Zohar 1999: 31)

$93 \mathrm{Na}$ teoría sistémica, este proceso de sanción duns modelos repertoriais sobre outros denomínase «canonización dinámica», en oposición á «canonización estática», que se realiza a nivel dos produtos (Even Zohar 1990: 19).

94 A subalternidade evidénciase tamén nos propios elementos do repertorio lexitimado, en moitos casos derivados ou dependentes do sistema do que se quere individualizar o sistema de oposición (Beramendi 1991: 136). A falta de autonomía plena dun sistema emerxente fai que tamén compareza, e con moita enerxía, 
CAStro, O. / M. LiÑEIRA (eds.) (2015): Trama e urda. Contribucións multidisciplinares desde os estudos galegos, Santiago de Compostela, Consello da Cultura Galega. doi:10.17075/tucmeg.2015.

diversifiquen $^{95}$ o limitado agregado de fórmulas dispoñíbeis nese estado concreto do sistema. ${ }^{96}$

E, continuándomos nun sistema emerxente, quen se vai situar no grupo dos que despregan a enerxía inmobilista, contraria ás innovacións repertoriais, e quen no da enerxía rebelde, que foxe das limitacións dos modelos sancionados? Fóra dos contrarios á planificación cultural alternativa á dominante —que poderán aparecer circunstancialmente como defensores dos limitados modelos repertoriais sancionados nas etapas iniciais do sistema unicamente como consecuencia da súa resistencia a asumir que $\mathrm{o}$ repertorio alternativo se densifique $\mathrm{e}$ fortaleza-, o posicionamento nunha ou noutra facción vai depender de moitos factores, mais nós queremos agora chamar a atención sobre un, que tentaremos, ademais, exemplificar nun autor teatral.

Estamos a falar da percepción que un axente pode ter de se encontrar situado en lugares centrais dun campo cultural —embora este sexa emerxente-, percepción que o leva a reivindicar a historia que ten levado ao campo a este estado concreto de cousas — tamén a protexer o lugar que el propio ocupa no mesmo- e a se defender dos elementos - produtores, fórmulas de repertorio, etc. - que desequilibren esta situación dada tan favorecedora para os seus intereses en termos, por exemplo, de prestixio. ${ }^{97}$

Neste traballo pretendemos constatar estas tensións nun exemplo tirado do sistema teatral galego da terceira década do século XX, en concreto da peza en dous actos Un caso compricado, escrita por Leandro Carré Alvarellos (1888-1976) a finais de 1922 e estreada polo Real Coro «Toxos e Froles» de Ferrol en xullo de 1928.

Non hai moitas dúbidas a respecto de que o autor desta obra dramática facía parte da elite cultural ocupada en fornecer modelos repertoriais alternativos ao sistema español ${ }^{98}$ —no seu caso fundamentalmente teatrais - coa intención de

a forza exercida polo sistema de oposición, contraria, como é lóxico, á asunción social dun repertorio alternativo extenso e fortalecido.

95 Even-Zohar explica a partir da denominada «lei de proliferación» a perentoria necesidade dos sistemas emerxentes de se dotaren, para alcanzaren a autosuficiencia, dun crecente número de posibilidades repertoriais alternativas (Even-Zohar 1990: 26). Por iso, de se conseguir, o alargamento repertorial iría fortalecer o sistema emerxente fronte ao sistema dominante co que loita polo espazo social.

96 Pensemos, xa na literatura galega, no exemplo da lírica no paso do século XIX ao XX: a súa consideración como xénero central da produción literaria galega dificultaba enormemente a emerxencia e consolidación doutros xéneros.

97 Inclusivamente, unha vez subvertido o estado do campo en que o axente concreto ocupaba un lugar privilexiado, este poderá reivindicar a lembranza do momento en que a situación era para el máis prestixiosa, para valerse dun capital simbólico herdado de situacións anteriores.

${ }^{98}$ Leandro Carré foi membro das Irmandades da Fala da Coruña, fundou a editorial Lar, fixo parte do Seminario de Estudos Galegos etc. Aliás, escribiu unja gramática e un diccionario galego-español. 
CAStro, O. / M. LiÑEIRA (eds.) (2015): Trama e urda. Contribucións multidisciplinares desde os estudos galegos, Santiago de Compostela, Consello da Cultura Galega. doi:10.17075/tucmeg.2015.

alcanzar unha Galiza cohesionada socialmente á volta dunha rede autónoma de relacionamentos ${ }^{99}$, delimitada polo uso da lingua do país. ${ }^{100}$

A vontade de ollar para o futuro e superar os modelos caducos do teatro galego está tamén moi presente en Leandro Carré, pois a conferencia ditada en 1923 so o título «A moderna orientación do teatro galego» inclúe a epígrafe «É mester mirar adiante», en que podemos ler: «[...] é preciso corresponder â afición e entusiasmo do pobo ofrecéndolle cousas mais perfeitas cada día, xa que cada día tamén, vaise depurando o seu gusto e adiantando na sua educación estética, ademais de que o artista en maneira algunha ha de se limitar á satisfacer pol-o momento a limitada comprensión e o gusto d'unha parte do actual auditorio das obras galegas, senon que ha de pensar no porvir» (Carré 1923).

Ora, a cuestión é definir onde colocaba Carré o teito para esas innovacións, o límite que podía atinxir o producido teatralmente en lingua galega, pois o autor discordou fortemente da vía naturalista escollida polo Conservatorio Nacional de Arte Galega. ${ }^{101}$ A razón haberá que procurala no habitus ${ }^{102}$ desde autor, pois, con efecto, Carré estaba embebido de exemplos rexionalistas e dos modelos calderonianos do teatro español que chegaba naquela altura aos teatros coruñeses. Sen dúbida, o grande modelo galego de Carré en materia teatral era Galo Salinas (1852-1921), ao que o unira unha forte simpatía e proximidade. ${ }^{103}$ Aliás, Carré percibíase como un continuador director do realizado pola Escola Rexional de Declamación e, fronte aos excesos naturalistas que el vía en obras como as de Quintanilla e as desordes cómicas dalgunhas obras, el propio definía os seus títulos en negativo, isto é, polo que non tiñan. Así, $O$ Engano (publicada en 2011, aínda que escrita en 1919) «non é unha comedia de chistes nin de situacións cómicas; non é tampouco un drama en que hai riñas, mulleres

\footnotetext{
${ }^{99}$ A teoría do polisistema explica a cohesión social a partir do éxito na introdución de repertorios culturais alternativos: «[...] unidades como "pobo", "nación" non son obxectos "naturais" [...], senón que se configuran mediante a acción de individuos ou de pequenos grupos que toman iniciativas e acertan na mobilización dos medios necesarios para tales fins. O elemento clave entre estes medios é un repertorio cultural que fai que o grupo que se esforza en introducir os cambios proporcione, non só modelos efectivos, senón a xustificación da existencia (separada e distinta) da entidade» (Even-Zohar 1998: 481).

${ }^{100}$ Carré foi claro a este respecto: «E ao me referir ao Teatro Galego, non falo naturalmente mais que do escrito na nosa fala, porque eu non podo en maneira algunha considerar como obras galegas á todas aquelas que, ainda tratando de copiar tipos da terra, son escritas en castelán» (Carré 1923).

${ }^{101}$ Carré gostou de A man de Santiña, de Cabanillas, a primeira obra encenada polo Conservatorio, mais rexeitou con enerxía os modelos naturalistas defendidos desde a dirección desta institución: «O teatro non debe ser copia exacta da realidade» (Carré 1923) e «A arte dramática debe ser a creación de algo novo, que ainda lembrando a vida real, na que se inspira, tenda ao ideal, espertando no espectador un sentimento de beleza, unha emoción purificadora e educativa» (Carré 1923).

${ }^{102}$ Pierre Bourdieu define o habitus como o «système de schèmes de perception et d'appréciation, comme structures cognitives et évaluatives qu'ils acquièrent à travers l'expérience durable d'une position dans le monde social» (Bourdieu 1987: 156).

${ }^{103}$ Son tales as gabanzas de Leandro Carré ao teatro de Salinas que, nalgún caso, chegamos a ter algún exemplo de excusatio non petita coa que tenta xustificar a súa entrega ao dramaturgo rexionalista: «Non coidedes, noustante, que por simpatía hacia o autor gabo a sua obra, non» (Carré 1961: 168-169).
} 
CAstro, O. / M. LiÑEIRA (eds.) (2015): Trama e urda. Contribucións multidisciplinares desde os estudos galegos, Santiago de Compostela, Consello da Cultura Galega. doi:10.17075/tucmeg.2015.

deshonradas, nin escenas altisonantes» (Carré 1923) e, tamén segundo as súas palabras, $O$ Pecado alleo (1924) non é «[...] un drama de situacións violentas, de berros, de actitudes descompostas, de desesperacións clamorosas» (Carré 1923). Polos vistos, o decoro era un asunto de primeira orde para o dramaturgo coruñés.

Mais independentemente dos gustos estéticos, o habitus inclúe tamén un outro contido que ten a ver cos intereses de posicionamento na estrutura social, pois, como xa se adiantou (vid. nota 11), a percepción e a apreciación das prácticas artísticas expresan a posición de quen realiza ambas as operacións. Leandro Carré comezara a súa acumulación de capital simbólico a partir do contacto con Salinas e os dramaturgos rexionalistas, que lle abriran ao mozo coruñés, despois dunha breve estada no Porto, o camiño que o levaría a dirixir en 1917 o cadro de declamación do coro coruñés "Cántigas da Terra» - posteriormente tamén o do coro «Saudades», xunto con Mauricio Farto- e en 1922, após a tentativa de crear unha escola alternativa ao fanado Conservatorio, o cadro de declamación da Irmandade de Coruña, que pasará a denominarse Escola Dramática Galega (Tato 1999). Na mesma liña, a súa primeira peza teatral, Noite de ruada (escrita en 1910) é absolutamente debedora dos modelos rexionalistas que tanto o marcaron. E a obstinación de Carré de constituír un grupo teatral galego $^{104}$ tamén está relacionada coa empresa de Salinas e Sánchez Miño -promotores en 1903 da Escola Rexional de Declamación e, o segundo, da Escola Dramática Galega fundada en 1908 en Ferrol-, xunto co exemplo da agrupación amadora que coñece no Porto.

Leandro Carré era consciente de que o incipiente sistema teatral sairía moi fortalecido da concorrencia dun grande número de modelos repertoriais diferentes e mesmo antagónicos. Con todo, o seu traballo cos coros e a Escola Dramática Galega permitíralle, dun lado, saber de primeira man cal era o horizonte de expectativas dos espectadores que constitúan o groso do público do teatro galego —afeitos á comedia, ao costumismo, ás personaxes arquetípicas, ás tramas de enredo, ao ruralismo, etc. - , e, doutro, coñecer as características dos eventuais intérpretes que poderían encarnar os textos dramáticos escritos na nosa lingua: amadores voluntaristas sen formación ningunha. Neste último aspecto, o propio dramaturgo proclamaría: «O que faltan son actores» (Carré 1923). Seguía así, máis unha vez, a Galo Salinas, que apuntara esta carencia como unha das causas do pouco desenvolvemento da arte dramática na Galiza.

${ }^{104}$ O seu biógrafo Xosé Manuel Maceira infórmanos do temperá que esta idea foi: «O 7 de marzo de 1915 xa insistía na necesidade de construír un teatro galego e argumentaba dúas ideas constantes durante toda a vida: a existencia dun repertorio de calidade e a viabilidade dunha compañía que representase obras galegas, que mesmo podería ser "un bon negocio". Por iso, cando houbo a posibilidade de consolidar un coro na cidade da Coruña foi un dos colaboradores máis entusiastas» (Maceira 2005 I: 374). 
CAStro, O. / M. LiÑEIRA (eds.) (2015): Trama e urda. Contribucións multidisciplinares desde os estudos galegos, Santiago de Compostela, Consello da Cultura Galega. doi:10.17075/tucmeg.2015.

Desde a década de vinte do século pasado, Leandro Carré autopercibiuse como posuidor dun importante capital simbólico ${ }^{105}$ —nun momento en que era pouco o prestixio que circulaba entre os dramaturgos galegos, debido ao momento de emerxencia que vivía o sistema- e cando as circunstancias socio-políticas dificultaron a transmisión do producido neses anos, el foi un dos que máis traballou pola difusión e conservación do realizado: noutras palabras, pola preservación da fotografía do momento do campo en que el ocupaba un espazo próximo á centralidade. ${ }^{106}$

Evidentemente, esta non era a única intención de Carré cando reivindicaba o pasado, pois é igualmente certo que a exixencia do coñecemento da súa historia é síntoma de madureza do propio campo (Bourdieu 2004: 79) e, en último termo, fonte de lexitimación fronte aos que tenten desacreditalo. Mais defender o sistema e a súa historia cando se fixo parte dela é reivindicarse tamén un propio. Aliás, para reivindicar o seu nome no conxunto de activos do teatro galego, Carré ponderaba especialmente a súa figura de dramaturgo-actordirector, fronte aos que moraban unicamente no campo da literatura. ${ }^{107}$

Para deixar de repetir o xa reiteradamente feito nun campo e innovar, probabelmente sexa preciso recoñecer as limitacións do realizado anteriormente, ou, simplemente, que os modelos repertoriais produtivos até un momento dado teñen chegado a un punto de estancamento. Leandro Carré estivo disposto desde moi cedo a tratar calquera tipo de tema ${ }^{108}$ e a incorporar as ambientacións urbanas e as personaxes de camadas sociais elevadas. ${ }^{109}$ Ora ben, é até certo punto normal que percibise que o triunfo de novidades representaban para el un risco de deslocamento cara a posicións máis periféricas: as innovacións - tamén as que afectan aos modelos repertoriais sancionados - deveñen en ameazadoras por provocaren unha mudanza na rede de relacións que caracteriza

\footnotetext{
105 Así, nos seus artigos e ensaios sempre incluíu o seu nome e algunhas das súas obras entre os máis importantes do teatro galego.

${ }^{106}$ Falamos de artigos como «¿Houbo denantes de agora teatro galego?» (1975), «Apontamentos para a historia do teatro galego» (1931), «Literatura galega. Teatro» (1961) e tantísimos outros de teor semellante.

107 «Se botamos unha ollada aos grandes escritores dramáticos, vemos que coase sempre os que mais fama abrangueron pol-as suas obras xeniales son aqueles que, como Molière e Shakespeare, eran ao mesmo tempo actores; e xa nos tempos modernos, un dos que marcóu época e fixo escola, Ibsen, conoscía tamén de perto a mecánica e mais o espírito do Teatro, porque durante moitos anos foi direitor de escena no Teatro de Cristianía, e durante algun tempo adicouse tamén ao estudo da arte escénica en Dinamarca e Alemania» (Carré 1923).

${ }^{108}$ Así o recoñecía Carré no texto co que gañou en 1964 o concurso «Nieto Pena», titulado «Pol-a creación d'un teatro galego do noso tempo»: «Os temas son a esencia, a razón de ser da obra mesma; e como a literatura, sexa teatro, novela ou poesía, é unha arte e a arte é universal, o autor dramático ha procurar dotar â sua obra, libremente, de un valor propio e orixinal, sen se sometere única e forzosamente a tópicos rexionaes locales, nen a encaixillados que limiten a sua ideia, a sua esgrevia ilusión de lograre unha obra con caraiter de universalidade, se ben esto non sexa doado de acadar; mais, hai que intentalo» (Carré 2006: 65).

${ }^{109}$ Carré (1929) chegaría a propor como modelo «que pudiera contribuir grandemente al robustecimiento de la escena gallega» o «sainete de costumbres ciudadanas», habitual no teatro burgués español e perfectamente conciliábel co habitus do dramaturgo coruñés.
} 
CAStro, O. / M. LiÑEIRA (eds.) (2015): Trama e urda. Contribucións multidisciplinares desde os estudos galegos, Santiago de Compostela, Consello da Cultura Galega. doi:10.17075/tucmeg.2015.

o sistema e poderen deslocar o prestixio — a centralidade - a outros espazos do campo.

Así se explica que aquelas innovacións repertoriais que escapaban ao seu habitus fosen consideradas pexorativamente por Carré. Desta maneira, as novidades de Donosiña e Alén recibiron o cualificativo de «exóticas» e «cinematográficas» ${ }^{110}$ e tórnase definitiva a súa afirmación: «En Galicia houbo quen quixo meterse á innovador no noso Teatro, e toda a novedade que se lle ocurríu foi suprimir a división por escenas, iñorando que esto é producto da necesidade mecánica da representación» (Carré 1923).

Parece altamente probábel que Leandro Carré Alvarellos coñecese as principais obras de August Strindberg, Henrik Ibsen, Maurice Maeterlink e Anton Tchekhov, pois el propio afirmou a propósito das obras da súa autoría que «en todas elas tratei de facer arte seguindo un rumo de modernidade d'acordo cô que puiden adeprender nas obras do teatro noruego, ruso, dinamarqués e alemán á cuio estudo adiqueime, e que deixaron na miña alma unha visión de sentimento ideal» (Carré 1923). Cousa diferente é a permeabilidade que fose quen de mostrar a respecto destes modelos teatrais, transferencias intersistémicas que ían depender, como xa vimos, do seu propio habitus.

\section{UN CASO COMPRICADO}

Imos comprobar estas tensións entre a vontade de alargamento e modernización dos repertorios galegos e o desexo de conservar a caracterización do sistema nun momento dado e resistirse á introdución de elementos agresivos respecto do seu propio habitus nunha obra concreta de Leandro Carré, editada en 2011 por primeira vez en libro.

Estamos a falar de Un caso compricado, peza escrita con toda probabilidade a finais de 1922 e subtitulada polo autor como «comedia en dous actos». Dela coñecemos dúas encenacións diferentes (Biscainho 2011: 68-69), que foron levadas ao palco, respectivamente, en 1928 (Teatro Xofre de Ferrol) e en 1930 (Salón Campoamor da Graña e Salón Severa de Fene), ambas polo Real Coro «Toxos e Froles» de Ferrol so a dirección de José Castro Moreno. Segundo

\footnotetext{
110 «Denosiña e Alem, de Quintanilla, son duas obras exóticas pol-os tipos, pol-o ambente e pol-o asunto. A primeira parece inspirada nas cousas francesas en que abondan os maridos enganados, as cobizosas aventureiras, os bandidos que se finxen amigos dos que explotan, e hastra os cínicos chantaxistas. Somella como se Quintanilla quixera satisfacer co'esta obra os gustos do púbrico afeito âs producciós cinematográficas por series en que se ven as cousas mais estranas» (Carré 1923).
} 
CAStro, O. / M. LiÑEIRA (eds.) (2015): Trama e urda. Contribucións multidisciplinares desde os estudos galegos, Santiago de Compostela, Consello da Cultura Galega. doi:10.17075/tucmeg.2015.

constaba no manuscrito autógrafo -hoxe desaparecido- ${ }^{111}$ a obra fora «Escrita expresamente para Toxos e Froles a cuia enxebre agrupación adícaa $\mathrm{O}$ Autor». ${ }^{112}$

O primeiro que chama a atención na estrutura da obra é a lonxitude, concretada na división en dous actos, en lugar dos tres que xa empregara Carré nalgún outro título anterior; para alén dun título de San Luís Romero, unicamente Quintanilla e Carré se decidiran a continuar esta liña iniciada por Lugrís Freire con Mareiras (1904). Sen dúbida, o feito de se tratar dunha peza que ía representar un coro non é alleo a esta estrutura, pois estas agrupacións adoitaban integrar as representacións en extensas veladas musicais, das que o teatro non deixaba de ser un apartado máis (Tato 1995). $\mathrm{Na}$ altura da redacción de Un caso compricado, o seu autor sabe plenamente o funcionamento dos coros populares en relación ao teatro galego.

A acción desenvólvese nunha «vila calquera de pouca importancia» (Carré 2011), continuando co propósito do seu autor de incluír personaxes e localizacións non necesariamente rurais.

Canto á temática, o feito de a trama xirar á volta da resolución dun eventual crime e de o autor incluír entre as personaxes a un xuíz - que vai desenvolver unha serie de interrogatorios_- un escribán e un alguacil, leva inicialmente a considerar a obra de temática policial, de maneira que estariamos perante un dos primeiros exemplos de texto teatral galego destas características. ${ }^{113}$

Trátase, entón, dunha transferencia intersistémica coa que se pretende densificar os elementos e modelos repertoriais do teatro galego? $\mathrm{E}$, en concreto, para evitar recorrer á dramática española, referente de oposición do incipiente teatro galego, foi Carré procurar este formato nos autores europeos nos que dicía que se nutría o seu teatro. Aínda que a temática policial non era a máis abundante no primeiro cuartel do século nas dramaturxias escandinavas, rusa e alemá, encontramos, no entanto, algún exemplo moi significativo, como o Rosmersholm, de Ibsen, «[...] que mereció un breve y penetrante estudio de Sigmund Freud y que en cierto modo puede lerse como una compleja trama policíaca», segundo Víctor Gallego, que acrecenta:

\footnotetext{
111 Felizmente, temos unha transcrición do mesmo realizada por Laura Tato nos anos noventa, antes do seu desaparecemento.

112 Como xa dixemos noutro lugar (Biscainho 2011: 55), «A data de redacción de Un caso compricado (novembro-decembro de 1922) coincide cos primeiros meses da temporada en que Leandro Carré estivo á fronte da Escola Dramática Galega, polo que non parece insensato pensar que o dramaturgo escribise esta peza coa idea de estreala co cadro de declamación da Irmandade da Fala da Coruña e que, diante da imposibilidade de o facer após o advenimento da ditadura de Primo de Rivera, se decidise a regalala ao coro ferrolán».

${ }^{113}$ Laura Tato (1996) xa comentou a «mestura de folletín e comedia policial» presente na estrutura de Entre dous mundos, de Galo Salinas, e chamou a atención, igualmente, sobre a técnica de comedia policial empregada na resolución de Donosiña, de Quintanilla, mais ningunha delas podería ser consideradas propiamente obras policiais. En todo caso, estamos a nos referir a textos teatrais, pois o relato de Risco «Do caso que lle aconteceu ao doutor Alveiros», publicado en 1919, tiña xa algo a ver con este xénero.
} 
CAStro, O. / M. LiÑEIRA (eds.) (2015): Trama e urda. Contribucións multidisciplinares desde os estudos galegos, Santiago de Compostela, Consello da Cultura Galega. doi:10.17075/tucmeg.2015.

[...] una sombría residencia señorial, una joven viviendo con un respetado pastor protestante que ha renunciado a su cargo, un suicidio turbio y sin aclarar, pasiones sexuales calladas y culpables, un fantasmal caballo blanco que anuncia la muerte... Y todo ello en medio de intensos debates sobre modelos sociales, ansias de libertad, luchas entre tendencias conservadoras y renovadores, intereses personales, pasados oscuros e inconfesables, revelaciones letales y pavorosas, presagios inevitables de infelicidad. En realidad, Rosmersholm es la historia de un crimen, de un «crimen psíquico», como acuñó Strindberg en un artículo de la obra (Gallego 2006: 120)

Nada disto comparece no texto de Leandro Carré, que, pragmático e posibilista, sabía que estas personaxes e estas tramas, aínda que non estivesen tratadas de xeito realista e si recreadas como algo novo que tendese ao ideal e espertase sentimentos de beleza e emocións purificadoras e educativas no espectador, como vimos que defendía o autor (Carré 1923), escapaban moitísimo do horizonte de expectativas do público que acompañaba as encenacións galegas dos coros: xente acostumada a asistir a dramas sentimentais e comedias relaxadas, de ritmo rápido, cheas de personaxes estereotipadas e presentadas nun envoltorio interpretativo moi básico, ora caracterizado por unha declamación grandilocuente, ora por un tipismo na lingua e nas personaxes non exenta de exaxeracións (Tato 1995).

Se non estamos perante unha transferencia intersistémica tirada do teatro escandinavo, alemán ou ruso, aínda poderíamos pensar nun transvasamento do teatro español, neste caso moito menos enriquecedor posto que, en tanto que referente de oposición, estas transferencias axudan a diminuír a diferenza entre ambos os corpus identitarios -o emerxente e o consolidado, co que loita polo espazo social- e aumenta, así, a ameaza de rexionalización ou subsistematización.

Mais, inicialmente, non podemos desbotar a posibilidade de que Carré teña tomado o modelo policial das pezas deste xénero que algunhas compañías españolas de repertorio achegaban regularmente aos teatros das principais vilas galegas, onde gozaban dun público devoto a este tipo de temáticas.

Porén, o certo é que o hipotético modelo policial desaparece xa nas primeiras escenas de Un caso compricado, onde se expón o embrollo que haberá que investigar. $\mathrm{Na}$ verdade, son apenas algunhas personaxes as que ignoran o que realmente aconteceu, pois para o auditorio non hai tal intriga que deba descobrir: xa desde a sétima escena do primeiro acto — dúas após a escena dos tiros e o suposto crime- os espectadores saben a quen ían dirixidos os disparos e que non houbo asasinato ningún. $\mathrm{O}$ único que ten de descobrir o público é a motivación real do comportamento do criado da casa, quen provocou os tiros.

A intriga é substituída polo humor. Así, introdúcese na trama o roubo dun cocho —que se entrecruza co asasinato-, xógase coas palabras de xeito 
CAStro, O. / M. LiÑEIRA (eds.) (2015): Trama e urda. Contribucións multidisciplinares desde os estudos galegos, Santiago de Compostela, Consello da Cultura Galega. doi:10.17075/tucmeg.2015.

gracioso $^{114}$ e constrúense as personaxes en clave cómica: amante medorento que provoca risa, brutalidade exaxerada do pai da ofendida, caracterización paródica das personaxes desde o propio nome. ${ }^{115}$ En lugar das turbias personaxes de Ibsen, Carré constrúe personaxes arquetipicamente torpes e graciosas, coas que el propio e os coros populares tan ben se mexen. ${ }^{116}$

Tamén funcionará en clave cómica o feito de o público comprobar a torpeza do investigador, que desbota a versión certa dos feitos, e presenciar a escena do pai do tiroteado a procurar consolo no suposto asasino.

Aliás, fronte aos temas secundarios da obra de Ibsen que tomamos como exemplo - loitas políticas, maltrato psicolóxico, paixóns sexuais non confesas etc.- - aquí temos temas como a preocupación por non dar nas vistas ou os amores non consentidos, de grande tradición como elementos repertoriais no teatro español que facía parte do habitus de autor de Un caso compricado, mais do que o incipiente teatro galego teimaba en se emancipar. Carré incorporará até un transunto do gracioso do teatro español, na figura de Lucas.

\section{CONCLUSIÓNS}

Este texto dramático escrito en 1922 serviunos para comprobar como nun mesmo dramaturgo poden concorrer forzas contrapostas relativas á incorporación de novidades repertoriais que enriquezan as sancionadas —oficial ou oficiosamente- nun momento inicial dos sistemas incipientes, neste caso no teatral.

Puidemos observar como a tensión nun autor por enriquecer e diversificar os elementos, opcións e modelos produtivos vese contrarrestada por visións pragmáticas e posibilistas e, nomeadamente, pola necesidade de conservar un estado de cousas —un mapa de relacións e de distribución de capital- que resultan propicias ao autor - xa que o colocan en posicións privilexiadas-, refreando así calquera tipo de transferencia intersistémica real desde sistemas non ameazadores.

\footnotetext{
114 Como se pode ver en «Tamén poidera dar que o mesmo que supoñemos morto fose un vivo» e «Como que era un infeliz o tal Feliciano», entre outros moitos exemplos.

115 Por exemplo, Bonifacio é o nome daquel a quen todos temen, Feliciano é un pobre infeliz supostamente asasinado e o petulante xuíz chámase Modesto.

116 Lembremos que o oitavo número da serie «Teatro Galego», publicada por Carré nas páxinas de $A$ Nosa Terra en 1922, está dedicada ás «Características dos tipos galegos» (31 de agosto).
} 
CAStro, O. / M. LiÑEIRA (eds.) (2015): Trama e urda. Contribucións multidisciplinares desde os estudos galegos, Santiago de Compostela, Consello da Cultura Galega. doi:10.17075/tucmeg.2015.

\section{REFERENCIAS BIBLIOGRÁFICAS}

ALVARIÑO, Ramón [pseudónimo de Leandro Carré Alvarellos] (1922): «Teatro galego. Características dos tipos galegos (VIII)», A Nosa Terra (A Coruña), 169, 31 de agosto.

BERAMENDI, Justo (1991): «El partido galleguista y poco más. Organización e ideologías del nacionalismo gallego en la II República», en Justo Beramendi / Ramón Máiz (comps.), Los nacionalismos en la España de la II República, Madrid, Siglo XXI, 127170.

BISCAINHO FERNANDES, Carlos Caetano (2011): «Estudo introdutorio», en Leandro Carré, Teatro recuperado: O pago / O engano / Un caso compricado, A Coruña, Biblioteca-Arquivo Teatral «Francisco Pillado Mayor» da Universidade da Coruña, 787.

BOURDIEU, Pierre (1987): Choses dites, Paris, Editions de Minuit.

BOURDIEU, Pierre (2004): O campo literario, Santiago de Compostela, Laiovento.

CARRÉ Alvarellos, Leandro (1923): «As conferencias da Irmandade. A do irmán Carré Alvarellos: A moderna orientación do Teatro galego», A Nosa Terra, 184, 1 de maio.

CARRÉ Alvarellos, Leandro (1929): «¿Qué opina usted acerca del Teatro Gallego? Leandro Carré dice...», Vida Gallega, 412, 10 de abril.

CARRÉ, Leandro (1931): «Apontamentos para a historia do teatro galego», Boletín de la Academia Gallega, XXVI:235-240, 213-224.

CARRÉ, Leandro (1961): «Literatura galega. Teatro», Céltica (Porto), 3, 166-174.

CARRÉ, Leandro (1975): «¿Houbo denantes de agora teatro galego? », La Voz de Galicia, 9 de maio, 23.

CARRÉ Alvarellos, Leandro (2006): «Pol-a creación d'un teatro galego do noso tempo», en Obra inédita e esquecida, Ed. Xosé Manuel Maceira Fernández, Santiago de Compostela, Alvarellos, 57-68.

CARRÉ, Leandro (2011): Teatro recuperado: O pago / O engano / Un caso compricado, A Coruña, Biblioteca-Arquivo Teatral «Francisco Pillado Mayor» da Universidade da Coruña.

EVEN-ZOHAR, Itamar (1990): «Polysystem Theory», Poetics Today, 11: 1, 9-26.

EVEN-ZOHAR, Itamar (1998): «Planificación cultural e resistencia na creación e supervivencia de entidades sociais», A Trabe de Ouro IV:36, 481-489.

EVEN-ZOHAR, Itamar (1999): «Factores y dependencias en la Cultura. Una revisión de la Teoría de los Polisistemas», en Montserrat Iglesias Santos (comp.), Teoría de los Polisistemas, Madrid, Arco, 23-52.

GALLEGO, Víctor (2006): «En el centenario de Henrik Ibsen», Revisiones, 2, 120-135.

MACEIRA FERNÁNDEZ, Xosé Manuel (2005): Leandro Carré Alvarellos na literatura galega, 2 vols, Tese de doutoramento, Santiago de Compostela, Universidade de Santiago de Compostela.

TATO, L. (1995): Teatro e nacionalismo. Ferrol 1915-1936, Santiago de Compostela, Laiovento.

TATO, Laura (1996): O teatro galego e os coros populares (1915-1931), Tese de doutoramento, A Coruña, Universidade da Coruña.

(http://ruc.udc.es/dspace/handle/2183/1075) [última consulta: xuño, 2014].

TATO, Laura (1999): Historia do teatro galego. Das orixes a 1936, Vigo, A Nosa Terra. 